\title{
Synchrotron serial crystallography at 11C beamline of Pohang Light Source-II
}

\author{
Do-Heon Gu${ }^{1}$, Cheolsoo Eo ${ }^{2}$, Dong Tak Jeong ${ }^{2}$, Jeong-Sun Kim ${ }^{1}$ and Suk-Youl Park ${ }^{2, *}$ \\ ${ }^{1}$ Department of Chemistry, Chonnam National University, Gwangju 61186, Republic of Korea \\ ${ }^{2}$ Pohang Accelerator Laboratory, POSTECH, Pohang 37673, Republic of Korea \\ *Correspondence: navypsy@postech.ac.kr
}

Serial crystallography (SX) makes a significant contribution for time-resolved studies and forms the base of structural analysis at room temperature, with minimal radiation damage. Even though X-ray free electron laser provides a femtosecond scale X-ray pulse, high accessibility of synchrotron facilities gives a merit for application of SX experiment. Therefore, we performed serial synchrotron crystallography (SSX) of lysozyme crystals at room-temperature. Both fixed target and injector-based methods were used for SX experiments to determine the structure of lysozyme crystals. Approximately 19,600 and 40,000 diffraction images were collected during 40 and 80 min, for fixed target and injectionbased methods, respectively in the SSX experiments. The $10 \mathrm{~Hz}$ synchrotron X-ray radiation of the $11 \mathrm{C}$ beamline of the Pohang accelerator laboratory was used and the crystal structures of lysozyme were determined at $1.89 \AA$ and $1.80 \AA$ resolutions, respectively. These results provide experimental clues for routine SX at room temperature in synchrotrons.

\section{INTRODUCTION}

X-ray crystallography has become an essential method for clarifying the structures of proteins, as well as other organic and inorganic molecules (Watson and Crick, 1953; Anfinsen, 1973; Brockhouse and Shull, 1995; Shukla et al., 2013). Cryogenic electron microscopy (cryo-EM) has taken enormous strides (Wierman et al., 2019); however, X-ray crystallography remains the dominant tool in structural biology. Beyond the challenges in crystallizing protein samples, while maintaining an adequate size and shape, structural biologists are facing new challenges in the analysis of large biomolecular complexes and in understanding protein dynamics (Holton and Frankel, 2010). Therefore, there is a need for new methods to perform structural analysis at roomtemperature and study protein dynamics (Fraser et al., 2011; Grimes et al., 2018; Wierman et al, 2019).

Data collection from a single crystal at cryogenic conditions contributes to minimize the radiation damage (Garman, 2010), but it has limited capacity in elucidating protein dynamics and determining physiological structure. Serial crystallography (SX) using an X-ray free electron laser (XFEL) or storage ring (SR) light source enables determination of crystal structure at room temperature without radiation damage or low-dose damage, respectively (Chapman et al., 2011; Nogly et al., 2015; Weinert et al., 2017; Kim et al., 2018;. Wierman et al., 2019). SX merges tens of thousands of partial diffractions data generated from the diversely oriented hundreds of thousands microcrystals. The presence of a large number of microcrystals will allow the dispersion of the applied radiation, thereby minimizing radiation damage during the structural determination (Owen et al, 2017). These technological features enable observing the macromolecular intermediate state using time resolved analysis at room temperature (Panneels et al., 2015; Weinert et al., 2017; Wierman et al., 2019).

Compared with serial femtosecond crystallography (SFX) which can be performed with an XFEL, synchrotron serial crystallography (SSX) or serial millisecond crystallography (SMX) can be performed using the microfocusing undulator beamline of the SR light source. XFEL has the ability to generate shorter X-ray pulse at the femtosecond scale with more high flux photons compared to the milliseconds scale of the SR radiation. SSX holds some advantages, such as the current high accessibility and the fine-tuned stable X-ray beam. In addition, pre-developed experimental methods, such as the oscillation function, can allow high completeness with reduced diffraction images in SX (Meents et al., 2017; Wierman, 2019; de la Mora., 2020).

Two representative methods have been used for SSX experiments. The slurry is prepared by mixing the sample crystals with the delivery media using a sample injector (Liu et al., 2014; Weierstall et al., 2014; Fromme et al., 2015; Ishchenko et al., 2016; Moraes, 2016; Nogly et al., 2016; Kovácsová et al., 2017; Nam, 2019). In the first method, the crystal slurry passes though the aligned beam point and the images are recorded continuously by the detector. The second method is based on moving a fixed target sample holder using the raster scan option of the goniometer (Hunter et al., 2014; Mueller et al., 2015; Sherrell et al., 2015; Oghbaey et al., 2016; Owen et al., 2017; Roedig et al., 2017; Tolstikova et al., 2019; Lee et al., 2019). In this approach, the sample crystals are fixed in the holder that is perpendicularly aligned to the X-ray path. In the $2 \mathrm{D}$ raster scanning method, the diffraction images from the diversely oriented crystals are collected by the detector. 
To reduced consumption of crystal samples, the injector-based method utilizes a delivery media for mixing with crystal sample. In the X-ray exposure position, the stable and continuous crystal sample introduction has an effect on the completeness of data set (Grünbein and Nas Kovacs, 2019; Park and Nam, 2019). The delivery media, such as lipidic cubic phase (LCP) polyacrylamide (PAM) and shortening, confer viscosity to the mixing slurry for embedding crystals. Depending on the hydrophobicity and the environmental factors, such as temperature. It also diverse delivery media can be utilized for SX experiment. Injector based method has a merit for a short-time scale observation within protein complex with diverse ligands (Weierstall et al., 2014).

Compared to the injector methods, the fixed target method in SSX improves the availability of native crystals, without any preliminary treatment, such as mixing the sample with the delivery media. It also allows higher crystal hitting rate (Oghbaey et al., 2016; Owen et al, 2017; Shelby et al., 2020). Depending on the shape and material of the fixed target holder, diverse approaches on SX fixed target have been reported. Several materials have been tested for use in fixed target holder, including silicon (Zarrine-Afsar et al., 2012; Roedig et al., 2015), polymers (Feld et al., 2015; Baxter et al., 2016), Nylon mesh (Lee et al., 2019), and silicon or polymer chips with silicon nitride membranes (Frank et al., 2014; Hunter et al., 2014; Murray et al., 2015). Nonetheless, this method requires the optimization of handling for adequate holder preparation.

We introduce the SSX experiment at $11 \mathrm{C}$ microfocus beamline of the Pohang Accelerator Laboratory (PAL-BL11C) using the lysozyme crystals. Crystal structures were determined at room temperature at $1.89 \AA$ and $1.80 \AA$, using the fixed target and inject-based methods, respectively. Our approach in this study will be useful for data collection in the SSX experiment.

\section{METHODS}

Sample crystallization and preparation for SSX experiment

Lysozyme from chicken egg white was purchased from Hampton Research (Cat No. HR7-110; Aliso Viejo, CA, USA) and dissolved in $20 \mathrm{mM}$ sodium acetate $(\mathrm{pH} 4.5)$ to a final concentration of 100 $\mathrm{mg} / \mathrm{mL}$. Crystals suitable for synchrotron SX were obtained by mixing the lysozyme $(70 \mu \mathrm{L})$ with a buffer $(210 \mu \mathrm{L})$ containing 20 $\mathrm{mM}$ sodium acetate ( $\mathrm{pH} 4.5$ ), $0.9 \mathrm{M}$ sodium chloride, and 25\% ( $\mathrm{v} /$ v) ethylene glycol. The lysozyme crystals used in the experiment were $35-60 \mu \mathrm{m}$ and $<70 \mu \mathrm{m}$.

For fixed target serial crystallography, nylon mesh (pore size of $33 \mu \mathrm{m}$ and thickness of $330 \mu \mathrm{m}$ ) was purchased from Vision Lab Science (Inchon, Republic of Korea). The polyimide film was purchased from Covalue YoungJin Corporation (Daegu, Republic of Korea). The nylon mesh was installed within the fixed target holder and a drop of lysozyme crystal containing solution (30 $\mu \mathrm{M})$ was loaded on the mesh. Polyimide film covered the crystal loaded side and the opposite side was also covered with film.

For injector-based serial crystallography, the lysozyme crystals embedded shortening (Lotte samkang, Seoul, South Korea) was prepared using mechanical mixing. In a dual-syringe setup, the lysozyme $(20 \mu \mathrm{L})$ containing syringe (Hamilton, Cat No. 810651710RNR; Reno, Nevada, USA) was connected to a shortening $(80 \mu \mathrm{L})$ containing syringe. The contents in the two syringes were mechanically mixed without air bubble and were completely gathered on one side of syringe completely. The mixed crystal slurry was transferred from the sample syringe to the $\mathrm{X}$-ray beam point through silicone tube (Hanlab, Seoul, South Korea) using a syringe pump.

\section{Data collection}

The SSX was conducted at the microfocus MX (Macromolecular X-ray crystallography) experiment hutch at PAL-BL11C (Park et al., 2017). The used energy was $12.659 \mathrm{KeV}(0.97942 \AA)$ with photon flux of $\sim 1.3 \times 10^{12}$ photons within $100 \mathrm{~ms}$ duration. The $\mathrm{X}$-ray was focused to 8.5 (horizontal) $\times 4.1$ (vertical) $\mu \mathrm{m}^{2}$ (FWHM) using a KB (Kirkpatrick-Baez) mirror. The data collection was done at room temperature and the diffraction images were recorded using a PILATUS3 6M detector (Dectris, Baden-Daettwil, Switzerland) with $5 \times 12$ detector modules (pixel size: $172 \times 172 \mu \mathrm{m}$ ). The motion stage of raster scan was performed using a MD2-S X-ray Micro diffractometer (Arinax, Moirans, France). During data collection, the sample was maintained at room temperature $(298 \pm 0.2 \mathrm{~K})$.

For fixed target SX experiment, raster scanning was conducted. A $50 \mu \mathrm{m}$ translated position interval was set and the entire scanning area was fixed to $280 \times 280 \mu \mathrm{m}$. During raster scanning, the crystals within the holder were scanned from right to left every $50 \mu \mathrm{m}$ and the scan point was moved downwards by $50 \mu \mathrm{m}$, and the crystal scanning protocol was repeated in the below line. These scanning motions were repeated until data collection was complete (Figure 1).

For injector-based SX experiment, the syringe $(100 \mu \mathrm{L})$ containing the slurry of lysozyme crystals embedded shortening was mounted on a Fusion Touch 100 syringe pump (CHEMYX). After the perpendicular matching between the $\mathrm{X}$-ray beam
(A)

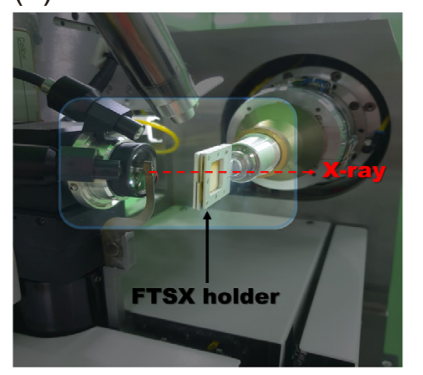

(B)

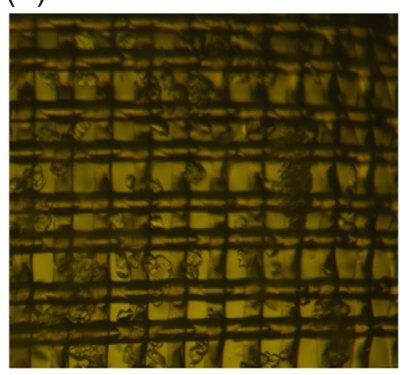

FIGURE 1 I Photograph of fixed target serial crystallography (FTSX) experiment at beamline $11 \mathrm{C}$ of the Pohang accelerator laboratory. (A) Photograph of fixed target method SX experiment. The SX sample holder is mounted directly on the gonio head of the MD2-S X-ray synchrotron diffractometer. The X-ray alignment axis is indicated as a red colored dashed arrow and the FTSX holder is indicated as a yellow colored dashed arrow. (B) Photograph of lysozyme crystals. Crystals were positioned on nylon mesh. 
position and the tip of transfer tube, the crystal slurry was extruded from the tip of tube at flow rates of $100 \mathrm{~nL} / \mathrm{min}$ by driven the pump. About the $80 \mu \mathrm{L}$ crystal slurry sample was consumed at the end of data collections (Figure 2).

\section{Data processing and structure determination}

The entire data collection was controlled using MxDC (Fodje et al., 2012) and the distinction between hit and not hit was performed using Cheetah (Barty et al., 2014). The filtered diffraction images were indexed, integrated, merged, and postrefined using Crystfel (White, 2019). The phasing of lysozyme was processed by molecular replacement using the Phaser-MR in PHENIX (Adams et al., 2010). The molecular model assembly and refinement with the electro density map was conducted with Coot (Emsley et al., 2010) and phenix.refine algorithms, respectively. Structural analysis and figure generation was performed using PyMOL (available at https://pymol.org/). The data collection and structural refinement statistics are
(A)

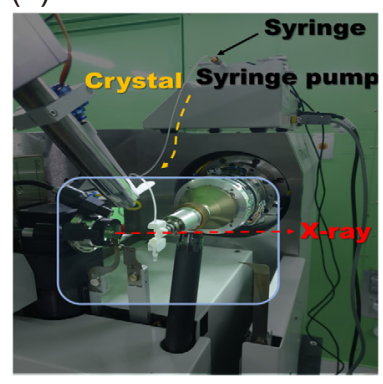

(B)

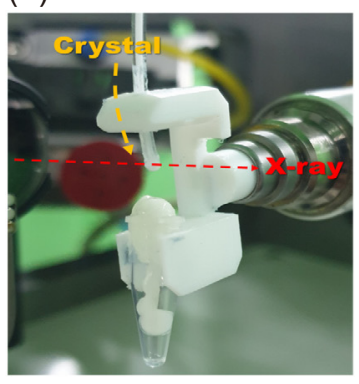

FIGURE 2 I Photograph of injector-based method serial crystallography (SX) experiment at beamline $11 \mathrm{C}$ of the Pohang accelerator laboratory. (A) Photograph of injector-based SX experiment. The crystal slurry containing tube was installed perpendicularly on the X-ray beam path. The X-ray alignment axis is indicated as a red colored dashed arrow and the direction of flow of crystal slurry is indicated as a yellow colored dashed arrow. (B) Closeup photograph showing the interaction point between the sample crystals and $\mathrm{X}$-ray. The crystal slurry was extruded from the silicone tube.

TABLE 1 | Data collection, scaling and structure refinement statistics

\begin{tabular}{|c|c|c|}
\hline Data Collection & Fixed target method & Injector-based method \\
\hline X-ray source & BL11C, PAL & BL11C, PAL \\
\hline Exposure time (ms) & 100 & 100 \\
\hline Beam size $(\mu \mathrm{m})$ & 8.5 (Horizontal) × 4.1 (Vertical) & 8.5 (Horizontal) $\times 4.1$ (Vertical) \\
\hline Wavelength $(\AA)$ & 0.97942 & 0.97942 \\
\hline Incident flux (photons s ${ }^{-1}$ ) & $1.3 \times 10^{12}$ & $1.3 \times 10^{12}$ \\
\hline No. of collected frames & 19,600 & 40,000 \\
\hline No. of integrated frames & 5,098 & 29,942 \\
\hline No. of images used & 3,806 & 3,597 \\
\hline \multicolumn{3}{|l|}{ Scaling } \\
\hline Space group & $\mathrm{P} 4_{3} 2_{1} 2$ & $\mathrm{P} 4_{3} 2_{1} 2$ \\
\hline \multicolumn{3}{|l|}{ Unit cell dimensions } \\
\hline $\begin{array}{l}a, b, c(\AA) \\
\alpha, \beta, \gamma\left({ }^{\circ}\right)\end{array}$ & $\begin{array}{l}78.90,79.17,37.39 \\
90.00,90.00,89.74 \\
\end{array}$ & $\begin{array}{l}79.49,79.52,38.21 \\
90.00,90.00,90.00 \\
\end{array}$ \\
\hline Resolution (Å) & $25.7-1.89(1.94-1.89)$ & $78.7-1.80(1.84-1.80)$ \\
\hline$R_{\text {split }}(\%)$ & $16.65(31.91)$ & $32.77(264.53)$ \\
\hline $1 / \sigma(l)$ & $4.8(3.2)$ & $1.8(0.5)$ \\
\hline CC & $0.96(0.71)$ & $0.856(0.098)$ \\
\hline $\mathrm{CC}^{*}$ & $0.99(0.91)$ & $0.960(0.423)$ \\
\hline $\begin{array}{l}\text { Multiplicity } \\
\text { Completeness (\%) }\end{array}$ & $\begin{array}{l}146.75(106.3) \\
100(100)\end{array}$ & $\begin{array}{l}54.516(29.2) \\
100(100)\end{array}$ \\
\hline \multicolumn{3}{|l|}{ Refinement } \\
\hline Resolution (Å) & $25.7-1.89$ & $27.93-1.80$ \\
\hline No. of reflections & 17,738 & 21,234 \\
\hline$R_{\text {work }} / R_{\text {tree }}(\%)$ & $22.81 / 24.57$ & $26.81 / 29.86$ \\
\hline No. atoms protein / water & $1001 / 44$ & $1001 / 44$ \\
\hline \multicolumn{3}{|l|}{ RMSD } \\
\hline bond lengths $(\AA)$ / angles $\left(^{\circ}\right)$ & $0.003 / 0.510$ & $0.004 / 0.568$ \\
\hline \multicolumn{3}{|l|}{ Ramachandran plot (\%) } \\
\hline favored / allowed / outliers & $98.43 / 1.57 / 0$ & $98.43 / 1.57 / 0$ \\
\hline
\end{tabular}

Values in parentheses are for the highest-resolution shell. $10 \%$ of the randomly selected reflections were used for calculating $R_{\text {tree }}$ values. 
summarized in Table 1.

\section{Highlight}

To apply the SX experiments to the routine crystallography beamline of synchrotron, we used the syringe pump with the delivery media for the injector-based method (Park and Nam., 2019) and the nylon mesh based sample holder for the fixed target method (Park et al., 2020). The high completeness of diffraction data set for analyzing the crystal structure is achieved by merging the partial diffraction images from the diversely oriented crystal. Therefore, the collection of diffraction data from the maximally diversely positioned crystals leads to the less sample consumption and experiment time (Weierstall et al., 2014). In this regard, the fixed target method utilizes the oscillation function of raster scan (Park et al., 2020). Thus, the sample holder can be rotated horizontally by maximum of $\pm 15^{\circ}$ on the raster scan to observe the more diverse crystal orientations for high multiplicity of crystal diffraction. Additionally, in the recent injection based experiment system, the silicone tube connected to syringe on the syringe pump was installed vertically on the goniometer (Figure 2). The crystal sample slurry was stably extruded to the X-ray interacting point without the curling of sample slurry caused by the previous syringe needle based system (Park and Nam., 2019).

For the injector-based method, we collected 40,000 images of the embedded lysozyme crystal shortening within $80 \mathrm{~min}$. After filtering the blank images, the numbers of 29,942 are filtered as a hit and 3,597 images were indexed. Post-refinement was conducted using partialator in CrystFEL. The results were processed up to $1.80 \AA$. The overall signal-to-noise ratio and completeness were $1.8 \%$ and $100 \%$, respectively. Overall $R_{\text {split }}$ and $\mathrm{CC}^{\star}$ were $32.77 \%$ and 0.96 , respectively.
For the fixed target method, the raster scan interval was set to $50 \mu \mathrm{m}$ for minimize radiation-induced damage and avoid potential physical alteration of the sample crystal. We collected 19,600 images within $40 \mathrm{~min}$ for the lysozyme structure. After processing the data with the Cheetah software, we obtained 5,098 diffraction images. After optimization of the detector geometry using geoptimise in CrystFel, 3,806 images among the observed diffractions were indexed with a rate of $74.7 \%$. Most diffraction images represented a single crystal diffraction pattern, but multiple hits also existed. Post-refinement was conducted using partialator in CrystFEL, and the results were processed up to $1.89 \AA$ resolution. The overall signal-to-noise ratio and completeness were 4.8 and $100 \%$, respectively. Overall $R_{\text {split }}$ and $\mathrm{CC}^{*}$ were $16.65 \%$ and 0.99 , respectively.'

Based on the results from both methods (Fixed target and injector-based), All identified residues belonged in lysozyme, which was positioned on a very clear electro density map (Figure $2 \mathrm{~A}$ and $2 \mathrm{C}$ ). The electro density map of four disulfide bonds (Csy 6-Csy 127, Csy 30-Csy 115, Csy 64-Csy 80, and Csy 76Csy 94 ) in the obtained structure was well defined, suggesting reduced radiation damage (Figure 3 ).

\section{CONCLUSION}

SSX applied in two representative methods was conducted on a BL11C at PAL. In this experiment, we utilized the shortening as a viscous medium for the fixed target holder. Based on the results, clear electron density map of lysozyme crystals at room temperature was available, both the SX methods were selectively applied for the experimental purpose. Each method has its own advantage, the stable sample introduction for injector-based method and the handy sample preparation for fixed target method, respectively. With these two SX experiment methods,
(A)

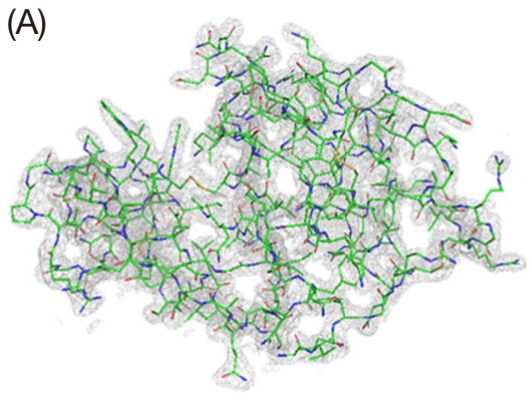

(C)

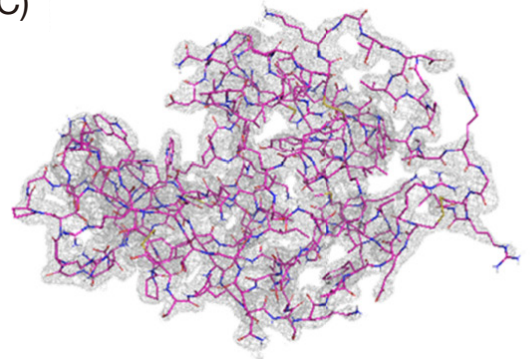

(B)

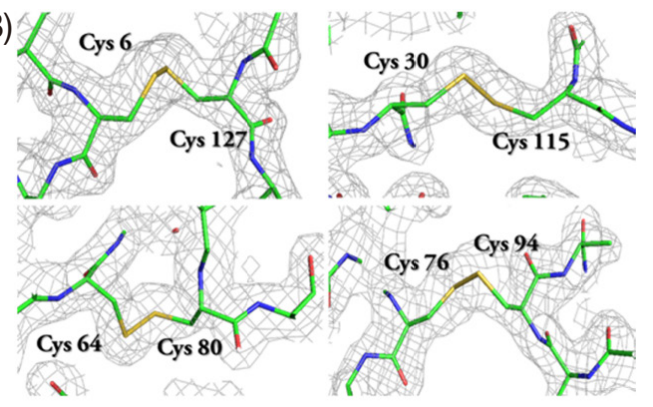

(D)

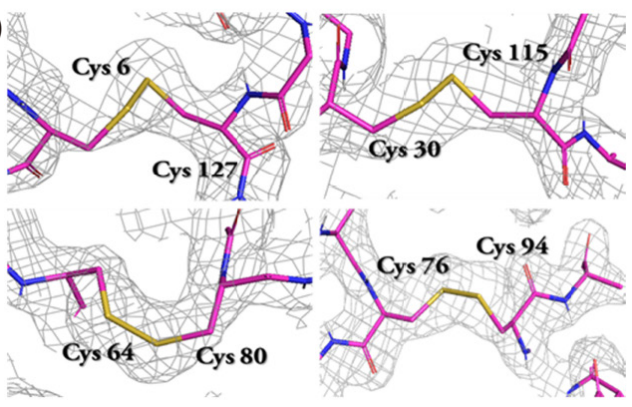

FIGURE 3 I Electron density map of lysozyme at room temperature. (A) $2 \mathrm{mFo}-\mathrm{Fc}$ electron density map of lysozyme obtained through the fixed target method. The electron density map is presented as a gray mesh at $1.0 \sigma$ and the assembled lysozyme model is shown as a stick. (B) Four different disulfide bonds within the lysozyme structure obtained through the fixed target method. (C) $2 \mathrm{mFo}-\mathrm{Fc}$ electron density map of lysozyme obtained through the injector-based method. The electron density map is presented as a gray mesh at $1.0 \sigma$ and the assembled lysozyme model is shown as a stick. (D) Four different disulfide bonds within the lysozyme structure obtained through the injector-based target method. 
we successfully conducted the SSX at room temperature. In future, we will enhance the efficiency of SSX data collection to allow the collection of a small number of diffraction images and still achieve complete crystal assessment by changing the angle of the goniometer and in the $11 \mathrm{C}$ beamline. These two straightforward SX experiments can be useful as the basic reference in general macromolecular crystallography beamline in the synchrotron.

\section{ACKNOWLEDGEMENTS}

The serial crystal X-ray diffraction experiment was performed with $11 \mathrm{C}$ beamlines at the Pohang Accelerator in Korea. This work was supported by "Development of the highly efficient crystal scanning and next generation fragment-based drug discovery system by XFEL" project (NRF Grant Number: NRF2017M3A9F6029736) and basic research project (NRF Grant Number: NRF-2019R1F1A1063023) of the National Research Foundation (NRF) of Korea.

\section{AUTHOR CONTRIBUTIONS}

S.Y. Park designed the study. All authors performed the experiments, analyzed data, and wrote the paper.

\section{CONFLICTS OF INTEREST}

The authors declare no potential conflicts of interest.

Original Submission: Sep 28, 2020

Revised Version Received: Nov 12, 2020

Accepted: Dec 2, 2020

\section{REFERENCES}

Adams, P.D., Afonine, P.V., Bunkóczi, G., Chen, V.B., Davis, I.W., Echols, N., Headd, J.J., Hung, L.W., Kapral, G.J., Grosse-Kunstleve, R.W., McCoy, A.J., Moriarty, N.W., Oeffner, R., Read, R.J., Richardson, D.C., et al. (2010). PHENIX: a comprehensive Python-based system for macromolecular structure solution. Acta Crystallogr D Biol Crystallogr 66, 213-221.

Anfinsen, C.B. (1973). Principles that govern the folding of protein chains. Science 181, 223-230.

Barty, A., Kirian, R.A., Maia, F.R., Hantke, M., Yoon, C.H., White, T.A., and Chapman, H. (2014). Cheetah: software for high-throughput reduction and analysis of serial femtosecond X-ray diffraction data. J Appl Crystallogr 47(Pt 3), 1118-1131.

Baxter, E.L., Aguila, L., Alonso-Mori, R., Barnes, C.O., Bonagura, C.A., Brehmer, W., Brunger, A.T., Calero, G., Caradoc-Davies, T.T., Chatterjee, R., Degrado, W.F., Fraser, J.S., Ibrahim, M., Kern, J., Kobilka, B.K., et al. (2016). High-density grids for efficient data collection from multiple crystals. Acta Crystallogr D Struct Biol 72, 2-11.

Brockhouse, B.N., and Shull, C.G. (1995). Announcement. Solid State Commun 93, 471.

Chapman, H.N., Fromme, P., Barty, A., White, T.A., Kirian, R.A., Aquila, A., Hunter, M.S., Schulz, J., DePonte, D.P., Weierstall, U., Doak, R.B., Maia, F.R., Martin, A.V., Schlichting, I., Lomb, L., et al. (2011). Femtosecond X-ray protein nanocrystallography. Nature 470, 73-77.

de la Mora, E., Coquelle, N., Bury, C.S., Rosenthal, M., Holton, J.M.,
Carmichael, I., Garman, E.F., Burghammer, M., Colletier, J.P., and Weik, M. (2020). Radiation damage and dose limits in serial synchrotron crystallography at cryo- and room temperatures. Proc Natl Acad Sci U S A 117, 4142-4151.

Emsley, P., Lohkamp, B., Scott, W.G., and Cowtan, K. (2010). Features and development of Coot. Acta Crystallogr D Biol Crystallogr 66, 486501.

Feld, G.K., Heymann, M., Benner, W.H., Pardini, T., Tsai, C.J., Boutet, S., Coleman, M.A., Hunter, M.S., Li, X., Messerschmidt, M., Opathalage, A., Pedrini, B., Williams, G.J., Krantz, B.A., Fraden, S., et al. (2015). Low-Z polymer sample supports for fixed-target serial femtosecond X-ray crystallography. J Appl Crystallogr 48, 1072-1079.

Fodje, M., Janzen, K., Berg, R., Black, G., Labiuk, S., Gorin, J., and Grochulski, P. (2012). MxDC and MxLIVE: software for data acquisition, information management and remote access to macromolecular crystallography beamlines. J Synchrotron Radiat 19, 274-280.

Frank, M., Carlson, D.B., Hunter, M.S., Williams, G.J., Messerschmidt, M., Zatsepin, N.A., Barty, A., Benner, W.H., Chu, K., Graf, A.T., HauRiege, S.P., Kirian, R.A., Padeste, C., Pardini, T., Pedrini, B., et al. (2014). Femtosecond X-ray diffraction from two-dimensional protein crystals. IUCrJ 1, 95-100.

Fraser, J.S., van den Bedem, H., Samelson, A.J., Lang, P.T., Holton, J.M., Echols, N., and Alber, T. (2011). Accessing protein conformational ensembles using room-temperature X-ray crystallography. Proc Natl Acad Sci U S A 108, 16247-16252.

Fromme, R., Ishchenko, A., Metz, M., Chowdhury, S.R., Basu, S., Boutet, S., Fromme, P., White, T.A., Barty, A., Spence, J.C., Weierstall, U., Liu, W., and Cherezov, V. (2015). Serial femtosecond crystallography of soluble proteins in lipidic cubic phase. IUCrJ 2, 545-551.

Garman, E.F. (2010). Radiation damage in macromolecular crystallography: what is it and why should we care? Acta Crystallogr D Biol Crystallogr 66, 339-351.

Grimes, J.M., Hall, D.R., Ashton, A.W., Evans, G., Owen, R.L., Wagner, A., McAuley, K.E., von Delft, F., Orville, A.M., Sorensen, T., Walsh, M.A., Ginn, H.M., and Stuart, D.I. (2018). Where is crystallography going? Acta Crystallogr D Struct Biol 74, 152-166.

Grünbein, M.L., and Nass Kovacs, G. (2019). Sample delivery for serial crystallography at free-electron lasers and synchrotrons. Acta Crystallogr D Struct Biol 75, 178-191.

Holton, J.M., and Frankel, K.A. (2010). The minimum crystal size needed for a complete diffraction data set. Acta Crystallogr D Biol Crystallogr 66(Pt 4), 393-408.

Hunter, M.S., Segelke, B., Messerschmidt, M., Williams, G.J., Zatsepin, N.A., Barty, A., Benner, W.H., Carlson, D.B., Coleman, M., Graf, A., HauRiege, S.P., Pardini, T., Seibert, M.M., Evans, J., Boutet, S., et al. (2014). Fixed-target protein serial microcrystallography with an $\mathrm{x}$-ray free electron laser. Sci Rep 4, 6026.

Ishchenko, A., Cherezov, V., and Liu, W. (2016). Preparation and delivery of protein microcrystals in lipidic cubic phase for serial femtosecond crystallography. J Vis Exp 20, 54463.

Kim, J., Kim, H.Y., Park, J., Kim, S., Kim, S., Rah, S., Lim, J., and Nam, K.H. (2018). Focusing X-ray free-electron laser pulses using KirkpatrickBaez mirrors at the $\mathrm{NCl}$ hutch of the PAL-XFEL. J Synchrotron Radiat 25, 289-292.

Kovácsová, G., Grünbein, M.L., Kloos, M., Barends, T.R.M., Schlesinger, R., Heberle, J., Kabsch, W., Shoeman, R.L., Doak, R.B., and Schlichting, I. (2017). Viscous hydrophilic injection matrices for serial crystallography. IUCrJ 4, 400-410.

Lee, D., Baek, S., Park, J., Lee, K., Kim, J., Lee, S.J., Chung, W.K., Lee, J.L., Cho, Y., and Nam, K.H. (2019). Nylon mesh-based sample holder for 
fixed-target serial femtosecond crystallography. Sci Rep 9, 6971.

Liu, W., Ishchenko, A., and Cherezov, V. (2014). Preparation of microcrystals in lipidic cubic phase for serial femtosecond crystallography. Nat Protoc 9, 2123-2134.

Meents, A., Wiedorn, M.O., Srajer, V., Henning, R., Sarrou, I., Bergtholdt, J., Barthelmess, M., Reinke, P.Y.A., Dierksmeyer, D., Tolstikova, A., Schaible, S., Messerschmidt, M., Ogata, C.M., Kissick, D.J., Taft, M.H., et al. (2017). Pink-beam serial crystallography. Nat Commun 8, 1281.

Moraes, I. The next generation in membrane protein structure determination Ch.11 (Springer, 2016).

Mueller, C., Marx, A., Epp, S.W., Zhong, Y., Kuo, A., Balo, A.R., Soman, J., Schotte, F., Lemke, H.T., Owen, R.L., Pai, E.F., Pearson, A.R., Olson, J.S., Anfinrud, P.A., Ernst, O.P., et al. (2015). Fixed target matrix for femtosecond time-resolved and in situ serial micro-crystallography. Struct Dyn 2, 054302.

Murray, T.D., Lyubimov, A.Y., Ogata, C.M., Vo, H., Uervirojnangkoorn, M., Brunger, A.T., and Berger, J.M. (2015). A high-transparency, micropatternable chip for X-ray diffraction analysis of microcrystals under native growth conditions. Acta Crystallogr D Biol Crystallogr 71, 1987-1997.

Nam, K.H. (2019). Sample delivery media for serial crystallography. Int J Mol Sci 20, 1094.

Nogly, P., James, D., Wang, D., White, T.A., Zatsepin, N., Shilova, A., Nelson, G., Liu, H., Johansson, L., Heymann, M., Jaeger, K., Metz, M., Wickstrand, C., Wu, W., Båth, P., et al. (2015). Lipidic cubic phase serial millisecond crystallography using synchrotron radiation. IUCrJ 2, 168-176.

Nogly, P., Panneels, V., Nelson, G., Gati, C., Kimura, T., Milne, C., Milathianaki, D., Kubo, M., Wu, W., Conrad, C., Coe, J., Bean, R., Zhao, Y., Båth, P., Dods, R., et al. (2016). Lipidic cubic phase injector is a viable crystal delivery system for time-resolved serial crystallography. Nat Commun 7, 12314.

Oghbaey, S., Sarracini, A., Ginn, H.M., Pare-Labrosse, O., Kuo, A., Marx, A., Epp, S.W., Sherrell, D.A., Eger, B.T., Zhong, Y., Loch, R., Mariani, V., Alonso-Mori, R., Nelson, S., Lemke, H.T., et al. (2016). Fixed target combined with spectral mapping: approaching $100 \%$ hit rates for serial crystallography. Acta Crystallogr D Struct Biol 72, 944-955.

Owen, R.L., Axford, D., Sherrell, D.A., Kuo, A., Ernst, O.P., Schulz, E.C., Miller, R.J., and Mueller-Werkmeister, H.M. (2017). Low-dose fixed-target serial synchrotron crystallography. Acta Crystallogr D Struct Biol 73, 373378.

Panneels, V., Wu, W., Tsai, C.J., Nogly, P., Rheinberger, J., Jaeger, K., Cicchetti, G., Gati, C., Kick, L.M., Sala, L., Capitani, G., Milne, C., Padeste, C., Pedrini, B., Li, X.D., et al. (2015). Time-resolved structural studies with serial crystallography: a new light on retinal proteins. Struct Dyn 2, 041718.

Park, S.Y., Ha, S.C., and Kim, Y.G. (2017). The protein crystallography beamlines at the Pohang Light Source II. Biodesign 5, 30-34.

Park, S.Y., and Nam, K.H. (2019). Sample delivery using viscous media, a syringe and a syringe pump for serial crystallography. $J$ Synchrotron Radiat 26, 1815-1819.

Park, S.Y., Choi, H., Eo, C., Cho, Y., and Nam, K.H. (2020). Fixed-target serial synchrotron crystallography using nylon mesh and enclosed filmbased sample holder. Crystals 10, 803.
Roedig, P., Ginn, H.M., Pakendorf, T., Sutton, G., Harlos, K., Walter, T.S., Meyer, J., Fischer, P., Duman, R., Vartiainen, I., Reime, B., Warmer, M., Brewster, A.S., Young, I.D., Michels-Clark, T., et al. (2017). High-speed fixed-target serial virus crystallography. Nat Methods 14, 805-810.

Roedig, P., Vartiainen, I., Duman, R., Panneerselvam, S., Stübe, N., Lorbeer, O., Warmer, M., Sutton, G., Stuart, D.I., Weckert, E., David, C., Wagner, A., and Meents, A. (2015). A micro-patterned silicon chip as sample holder for macromolecular crystallography experiments with minimal background scattering. Sci Rep 5, 10451

Shelby, M.L., Gilbile, D., Grant, T.D., Seuring, C., Segelke, B.W., He, W., Evans, A.C., Pakendorf, T., Fischer, P., Hunter, M.S., Batyuk, A., Barthelmess, M., Meents, A., Coleman, M.A., Kuhl, T.L., et al. (2020). A fixed-target platform for serial femtosecond crystallography in a hydrated environment. IUCrJ 7, 30-41.

Sherrell, D.A., Foster, A.J., Hudson, L., Nutter, B., O'Hea, J., Nelson, S., Paré-Labrosse, O., Oghbaey, S., Miller, R.J., and Owen, R.L. (2015). A modular and compact portable mini-endstation for high-precision, high-speed fixed target serial crystallography at FEL and synchrotron sources. J Synchrotron Radiat 22, 1372-1378.

Shukla, A.K., Manglik, A., Kruse, A.C., Xiao, K., Reis, R.I., Tseng, W.C., Staus, D.P., Hilger, D., Uysal, S., Huang, L.Y., Paduch, M., Tripathi-Shukla, P., Koide, A., Koide, S., Weis, W.I., et al. (2013). Structure of active $\beta$-arrestin-1 bound to a G-protein-coupled receptor phosphopeptide. Nature 497, 137-141.

Tolstikova, A., Levantino, M., Yefanov, O., Hennicke, V., Fischer, P., Meyer, J., Mozzanica, A., Redford, S., Crosas, E., Opara, N.L., Barthelmess, M., Lieske, J., Oberthuer, D., Wator, E., Mohacsi, I., et al. (2019). 1 kHz fixedtarget serial crystallography using a multilayer monochromator and an integrating pixel detector. IUCrJ 6(Pt 5), 927-937.

Watson, J.D., and Crick, F.H. (1953). Molecular structure of nucleic acids; a structure for deoxyribose nucleic acid. Nature 171, 737-738.

Weierstall, U., James, D., Wang, C., White, T.A., Wang, D., Liu, W., Spence, J.C., Bruce Doak, R., Nelson, G., Fromme, P., Fromme, R., Grotjohann, I., Kupitz, C., Zatsepin, N.A., Liu, H., et al. (2014). Lipidic cubic phase injector facilitates membrane protein serial femtosecond crystallography. Nat Commun 5, 3309.

Weinert, T., Olieric, N., Cheng, R., Brünle, S., James, D., Ozerov, D., Gashi, D., Vera, L., Marsh, M., Jaeger, K., Dworkowski, F., Panepucci, E., Basu, S., Skopintsev, P., Doré, A.S., et al. (2017). Serial millisecond crystallography for routine room-temperature structure determination at synchrotrons. Nat Commun 8, 542.

White, T.A. (2019). Processing serial crystallography data with CrystFEL: a step-by-step guide. Acta Crystallogr D Struct Biol 75, 219-233.

Wierman, J.L., Paré-Labrosse, O., Sarracini, A., Besaw, J.E., Cook, M.J., Oghbaey, S., Daoud, H., Mehrabi, P., Kriksunov, I., Kuo, A., Schuller, D.J., Smith, S., Ernst, O.P., Szebenyi, D.M.E., Gruner, S.M., et al. (2019). Fixedtarget serial oscillation crystallography at room temperature. IUCrJ 6, 305316.

Zarrine-Afsar, A., Barends, T.R., Müller, C., Fuchs, M.R., Lomb, L., Schlichting, I., and Miller, R.J. (2012). Crystallography on a chip. Acta Crystallogr D Biol Crystallogr 68, 321-323. 